Wright State University

CORE Scholar

Physics Faculty Publications

Physics

$10-1-2003$

\title{
Remote Hydrogen Plasma Processing of ZnO Single Crystal Surfaces
}

Yuri M. Strzhemechny

John Nemergut

Phillip E. Smith

Junjik Bae

David C. Look

Wright State University - Main Campus, david.look@wright.edu

See next page for additional authors

Follow this and additional works at: https://corescholar.libraries.wright.edu/physics

Part of the Physics Commons

\section{Repository Citation}

Strzhemechny, Y. M., Nemergut, J., Smith, P. E., Bae, J., Look, D. C., \& Brillson, L. J. (2003). Remote Hydrogen Plasma Processing of ZnO Single Crystal Surfaces. Journal of Applied Physics, 94 (7), 4256-4262.

https://corescholar.libraries.wright.edu/physics/154

This Article is brought to you for free and open access by the Physics at CORE Scholar. It has been accepted for inclusion in Physics Faculty Publications by an authorized administrator of CORE Scholar. For more information, please contact library-corescholar@wright.edu. 
Authors

Yuri M. Strzhemechny, John Nemergut, Phillip E. Smith, Junjik Bae, David C. Look, and Leonard J. Brillson

This article is available at CORE Scholar: https://corescholar.libraries.wright.edu/physics/154 


\title{
Remote hydrogen plasma processing of ZnO single crystal surfaces
}

\author{
Yuri M. Strzhemechny ${ }^{\text {a) }}$ \\ Center for Materials Research, The Ohio State University, Columbus, Ohio 43210 \\ John Nemergut \\ Department of Electrical Engineering, The Ohio State University, Columbus, Ohio 43210 \\ Phillip E. Smith and Junjik Bae ${ }^{\text {b) }}$ \\ Department of Physics, The Ohio State University, Columbus, Ohio 43210 \\ David C. Look \\ Air Force Research Laboratory, AFRL/MLPS, Wright-Patterson AFB and Semiconductor Research Center, \\ Wright State University, Dayton, Ohio 45435 \\ Leonard J. Brillson \\ Department of Electrical Engineering, Department of Physics, and Center for Materials Research, \\ The Ohio State University, Columbus, Ohio 43210
}

(Received 23 April 2003; accepted 17 July 2003)

\begin{abstract}
We have studied the effects of remote hydrogen plasma treatment on the defect characteristics in single crystal $\mathrm{ZnO}$. Temperature-dependent $(9-300 \mathrm{~K})$ and excitation intensity-dependent photoluminescence spectra reveal that $\mathrm{H}$-plasma exposure of $\mathrm{ZnO}$ effectively suppresses the free-exciton transition and redistributes intensities in the bound-exciton line set and two-electron satellites with their phonon replicas. The resultant spectra after hydrogenation exhibit a relative increase in intensity of the $I_{4}(3.363 \mathrm{eV})$ peak, thought to be related to a neutral donor bound exciton, and a peak feature at $3.366 \mathrm{eV}$ with a distinctly small thermal activation energy. Hydrogenation also produces a violet $100 \mathrm{meV}$ wide peak centered at $\sim 3.15 \mathrm{eV}$. Remote plasma hydrogenation yields similar changes in room-temperature depth-dependent cathodoluminescence spectra: the emission intensity increases with hydrogenation mostly in the violet and near-ultraviolet range. Subsequent annealing at $450^{\circ} \mathrm{C}$ within the same plasma environment completely restores both the photoluminescence and cathodoluminescence spectra in the subband gap range. The appearance of another bound-exciton feature at $3.366 \mathrm{eV}$ and a relative intensity increase of the donor-bound exciton at line $I_{4}$ with $\mathrm{H}$-plasma exposure, and the reversibility with annealing of the spectral changes, indicate a direct link between hydrogen indiffusion and appearance of a shallow donor. (C) 2003 American Institute of Physics. [DOI: 10.1063/1.1606859]
\end{abstract}

\section{INTRODUCTION}

$\mathrm{ZnO}$ has emerged as a promising semiconductor material for optoelectronic and high-temperature, high power microelectronics; yet its electrically active defect properties are relatively unexplored. ${ }^{1}$ Hydrogen-related defects have attracted significant attention recently because of their potential for tailoring $\mathrm{ZnO}$ properties. Today there is substantial experimental evidence that hydrogen affects $\mathrm{ZnO}$ in several ways, including the modification of electrical and optoelectronic properties, and the passivation of deep levels. For example, it was shown that hydrogen improves conductivity ${ }^{2-6}$ and increases the free electron concentration of $\mathrm{ZnO}^{7}$ Also, there were several reports demonstrating that hydrogen plasma treatment strongly passivates the green emission and enhances the band edge luminescence. ${ }^{8-11}$ Finally, there have been suggestions that hydrogen may be an important player in achieving a $p$-type $\mathrm{ZnO} .^{12}$ It is known that hydrogen is

\footnotetext{
a) Author to whom correspondence should be addressed; electronic mail: strzhemy@ee.eng.ohio-state.edu

${ }^{b}$ Currently at: ECE Department, Center for Quantum Devices, Northwestern University, Evanston, IL 60208.
}

typically a common impurity in $\mathrm{ZnO}$ because it is involved in nearly all growth processes of $\mathrm{ZnO}$ [vapor phase transport, hydrothermal, metalorganic chemical vapor deposition]. Also, hydrogen is most probably a fast-diffusing species in $\mathrm{ZnO} .^{7,13}$ A number of authors have suggested mechanisms of hydrogen influence on $\mathrm{ZnO}$ characteristics, e.g., passivation of deep defects by electron transfer ${ }^{7-11,14}$ or creation of a shallow donor because it is nonamphoteric. ${ }^{14-22}$ The latter aspect is attracting special attention lately in the collective effort to elucidate and engineer the conductivity type of the material.

There have been several studies of hydrogen processing of $\mathrm{ZnO}$, and most have involved a direct hydrogen plasma. $^{7-11}$ As a rule, this means that there is a direct contact of the plasma flame with the sample surface. This approach does not allow a thorough control of the surface temperature because when the sample is in an H-plasma sheath, the temperature is determined by the plasma interior, which makes it difficult to differentiate between thermally and chemically driven changes. To avoid this complication, in our studies we have used a remote plasma processing method. It allows a 
separate control and measurement of the temperature and pressure at the free surface of the specimen.

In this article we present findings on the influence of remote hydrogen plasma processing on single-crystalline $\mathrm{ZnO}$.

\section{EXPERIMENTAL DETAILS}

The $\mathrm{ZnO}$ samples studied here were cleaved from a nominally undoped single crystalline wafer grown by chemical vapor transport at Eagle-Picher Technologies and cut and polished normal to the $c$ axis. ${ }^{23}$ Typical values of the resistivity, carrier mobility, and free electron concentration for this material were previously measured to be $\rho=0.5 \Omega \mathrm{cm}$, $\mu=200 \mathrm{~cm}^{2} / \mathrm{V}$, and $n=6 \times 10^{16} \mathrm{~cm}^{-3}$, respectively.

In our experimental setup, ${ }^{24}$ a high-grade hydrogen gas was supplied into a vacuum chamber from a Parker-Balston hydrogen generator through a needle leak-valve and a quartz tube inductively coupled with an Advanced Energy RFX-600 radio-frequency generator. The plasma flame inside the quartz tube was controlled by the flow rate and pressure of the gas and the power supplied by the rf generator. The hydrogen flow rate, the gate valve on the turbo pump, and the turbo pump speed determined the amount of plasma leaking into the chamber. We employed a remote $\mathrm{H}$ plasma with the following parameters: $10 \mathrm{mTorr}$ of pressure and $30 \mathrm{~W}$ of power supplied by the rf generator. The samples were placed $\sim 20 \mathrm{~cm}$ downstream from the plasma-generating coil, on a stage wired to perform in situ annealing. In our experiments, annealing was rendered in the remote hydrogen plasma environment. We chose this approach in order to eliminate the possibility that plasma-induced impurities diffuse into the sample. In our plasma chamber, the samples are not shielded by a nonmetallic cover. The walls of the chamber and the sample holder may potentially exchange atoms with the surface of the sample since the remote plasma fills the entire chamber. If such species were to contaminate our surface as a result, their outdiffusion into the plasma ambient would be less likely than in a high-vacuum environment. Therefore, annealing of the H-plasma-exposed sample in the presence of the same plasma should promote outdiffusion of $\mathrm{H}$ rather than any other impurity.

A Kimmon IK HeCd laser with a wavelength of $325 \mathrm{~nm}$ was used to excite photoluminescence (PL). In the PL experiments, the sample was mounted inside an evacuated cryostat having a temperature range between 9 and $300 \mathrm{~K}$. A variable frequency chopper was employed to provide the reference signal. The cathodoluminescence (CL) experiments were performed in an ultrahigh vacuum chamber adjoining the processing chamber, where the hydrogenation was performed. An electron beam of variable energy and flux was electronically chopped. A more detailed description of the CL experimental apparatus appears elsewhere. ${ }^{25} \mathrm{~A}$ Carl Leiss single-flint-prism monochromator dispersed the CL intensity for spectral analysis. The PL signal was probed by an Oriel257 grating monochromator having a spectral resolution of $\sim 0.1 \mathrm{~nm}$. The CL and PL were detected by an S-20 photodetector connected to a Stanford Research lock-in amplifier. A Digital Instruments microprobe provided atomic force mi-
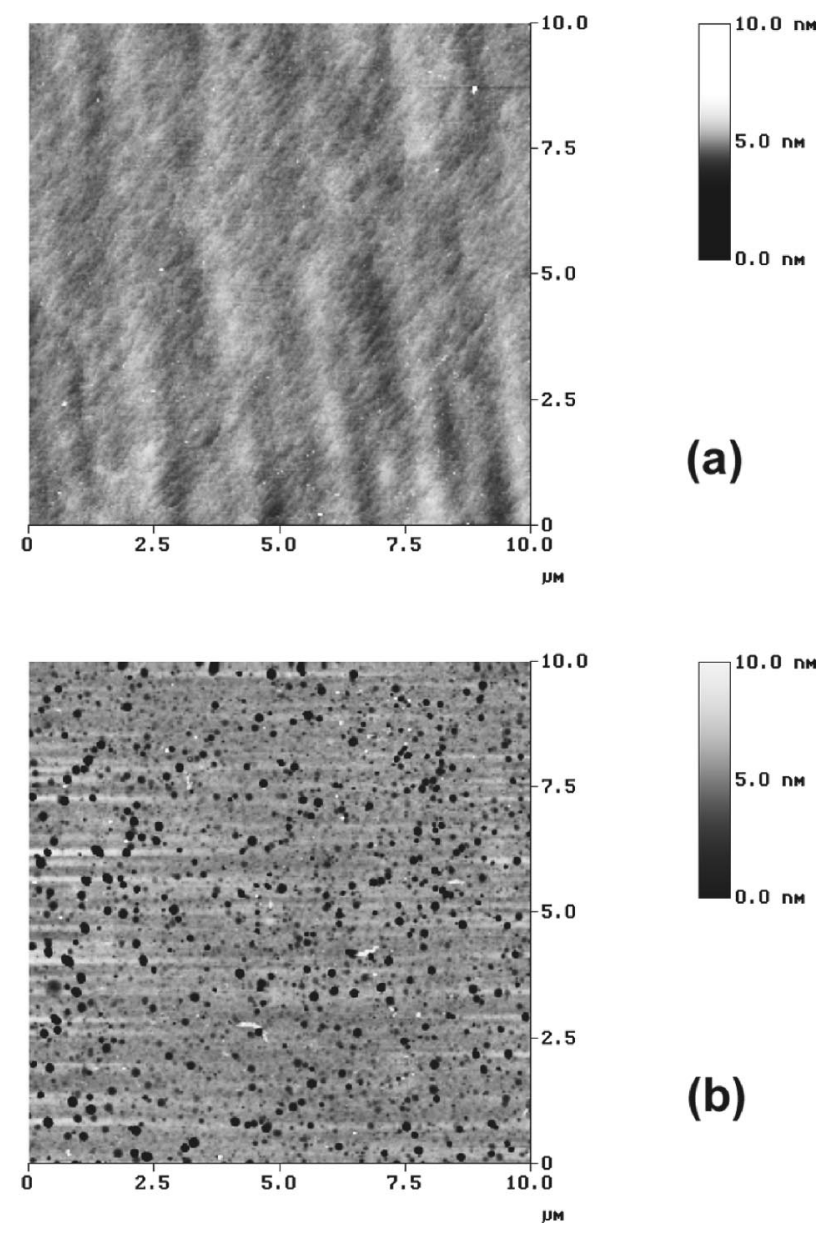

(a)

FIG. 1. AFM images of the Zn polar surfaces: (a) The smooth (rms roughness of $\sim 0.2 \mathrm{~nm}$ ) as-received surface reveals a periodic ledge structure probably due to a slightly misaligned plane of polishing. (b) The surface processed by the remote hydrogen plasma at room temperature is covered with shallow micropits $(\sim 20 \mathrm{~nm}$ deep and $\sim 200 \mathrm{~nm}$ in diameter $)$. The roughness of the surface between the pits is not significantly changed by hydrogenation.

croscopy (AFM) images. Prior to every step, we cleaned the samples with a standard sequence of organic solvents. All surface processing and characterization routines were performed on the $\mathrm{Zn}$ polar surface of the specimens.

\section{RESULTS AND DISCUSSION}

\section{A. AFM results}

Figure 1(a) shows an AFM scan for the as-received polar Zn surface. The surface appears very smooth, with a rms roughness of $\sim 0.2 \mathrm{~nm}$. The periodic ledge structure is probably the result of a slightly tilted polishing plane. A typical top-to-bottom dimension of a single ledge is of order of 1 nm. In Fig. 1(b), we display an AFM image of the Zn polar surface processed by the remote hydrogen plasma at room temperature. The surface is covered with micropits $\sim 20 \mathrm{~nm}$ deep and $\sim 200 \mathrm{~nm}$ in diameter. Despite their dark appearance in the AFM image, those pits are rather shallow. The roughness of the surface between the pits is not significantly altered although the ledge structure is no longer observable. 


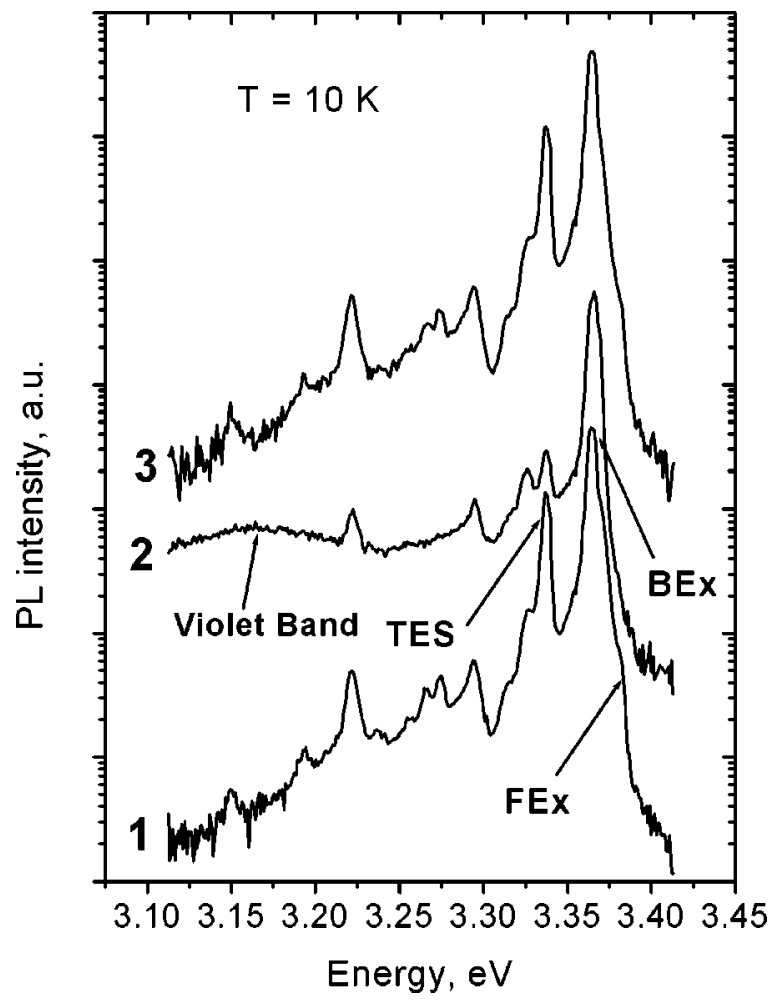

FIG. 2. PL results in the violet/UV spectral region, $T=10 \mathrm{~K}$, incident power $=10 \mathrm{~mW} / \mathrm{cm}^{2}$. (Curve 1) The as-received sample shows well-known transitions such as free excitons (FEx), bound excitons (BEx), two-electron satellites (TES), and their phonon replicas. (Curve 2) Remote plasma hydrogenation at room temperature lowers the BEx emission, significantly reduces the TES and replicas, and creates a broad violet feature at $\sim 3.15 \mathrm{eV}$. (Curve 3) Subsequent annealing in $\mathrm{H}$ plasma at $450{ }^{\circ} \mathrm{C}$ restores all violet and UV features.

\section{B. PL results}

In Fig. 2, we present PL spectra taken at $T=10 \mathrm{~K}$ and $10 \mathrm{~mW} / \mathrm{cm}^{2}$ of incident power for different processing stages of the sample. The spectrum obtained on the as-received sample revealed well-known features in the violet and ultraviolet (UV) range, such as a bound exciton band, a twoelectron satellite (TES) band, and several phonon replicas (curve 1). After remote plasma hydrogenation at room temperature for $30 \mathrm{~min}$, the PL spectra (curve 2) undergo significant changes. The integrated intensity of the bound exciton emission is weakened by a factor of $\sim 3$, the TES lines are suppressed to about $4 \%$ of the initial intensity, and a broad feature appears in the violet spectral region. Additional changes occur in the bound exciton region but are not resolved in this figure. A remarkable change takes place upon additional annealing of the same sample for $30 \mathrm{~min}$ at $450{ }^{\circ} \mathrm{C}$ in the same H-plasma environment: the spectral features in the violet and near-UV are completely restored (curve 3).

Figure 3 shows the evolution of the PL spectra in the near band edge region with higher energy resolution. The as-received sample shows well-known PL features such as bound and free exciton transitions (solid line). For this sample, the dominant emission features located in the bound exciton range are the $I_{4}$ and $I_{8}$ lines ${ }^{18,26}$ at 3.363 and 3.359 $\mathrm{eV}$, respectively. After room temperature remote plasma hydrogenation (dashed curve), the intensities of the $I_{4}$ and $I_{8}$

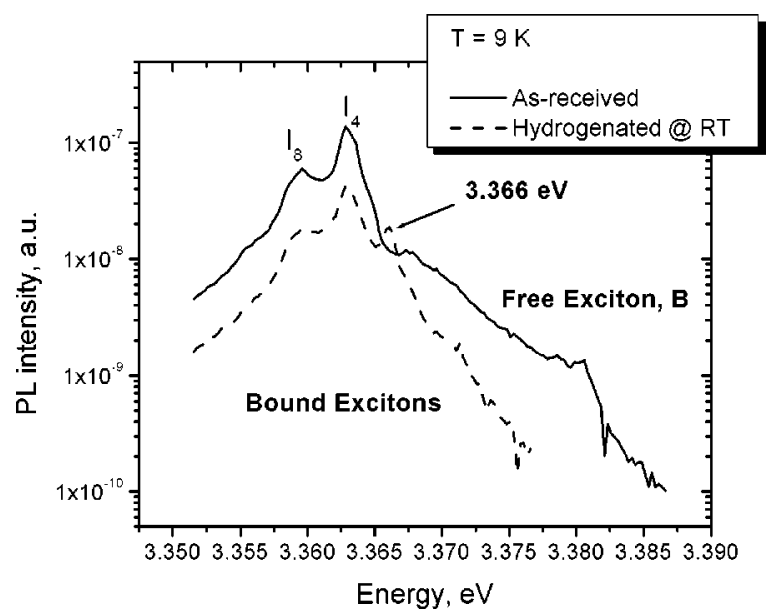

FIG. 3. Low-temperature PL in near-band edge region, $T=9 \mathrm{~K}$, incident power $=0.1 \mathrm{~W} / \mathrm{cm}^{2}$. (Solid line) As-received sample. Well-known bound (e.g., $I_{4}$ and $I_{8}$ ) and free exciton ( $B$ band) transitions are observed. (Dashed line) After room temperature remote plasma hydrogenation, the free exciton recombination is suppressed, the intensities in the bound exciton region are redistributed and a $3.366 \mathrm{eV}$ peak is added.

peaks drop, the free exciton recombination is almost fully suppressed, and another feature at $3.366 \mathrm{eV}$ appears in the bound exciton range. It is important to note that the intensity ratio $I_{4} / I_{8}$ almost doubles after hydrogenation, and the intensity of the $3.366 \mathrm{eV}$ feature is about the same as the intensity of $I_{8}$. The significance of this result will be considered in Sec. III D.

We performed temperature dependent PL experiments. For the as-received sample, the spectral evolution in the range 10-300 K coincided with what has been documented before (see, for example, Ref. 18). However, after room temperature plasma hydrogenation, almost all violet/near-UV features acquire significantly different temperature dependences. These changes are illustrated in Fig. 4, which compares PL spectra of the as-received and hydrogenated surfaces at $90 \mathrm{~K}$. The spectrum of the as-received sample is

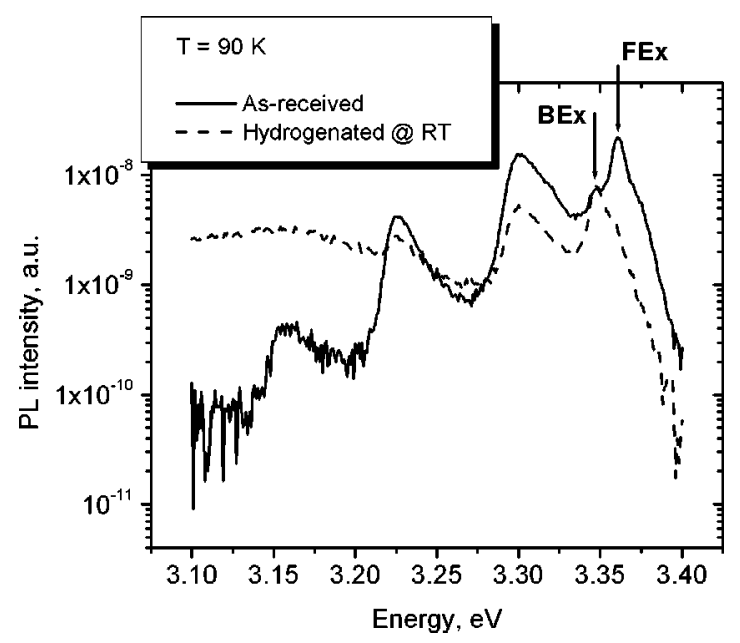

FIG. 4. $90 \mathrm{~K} \mathrm{PL}$ spectra in the violet/near UV region, incident power$10 \mathrm{~mW} / \mathrm{cm}^{2}$. (Solid line) For the as-received sample, the dominant FEx peak is at $3.374 \mathrm{eV}$. The BEx at $3.360 \mathrm{eV}$ is relatively weak. (Dashed line) RT-hydrogenated sample. The FEx peak is suppressed, and the dominant peak at $3.360 \mathrm{eV}$ is a BEx emission. Clear violet luminescence is present. 


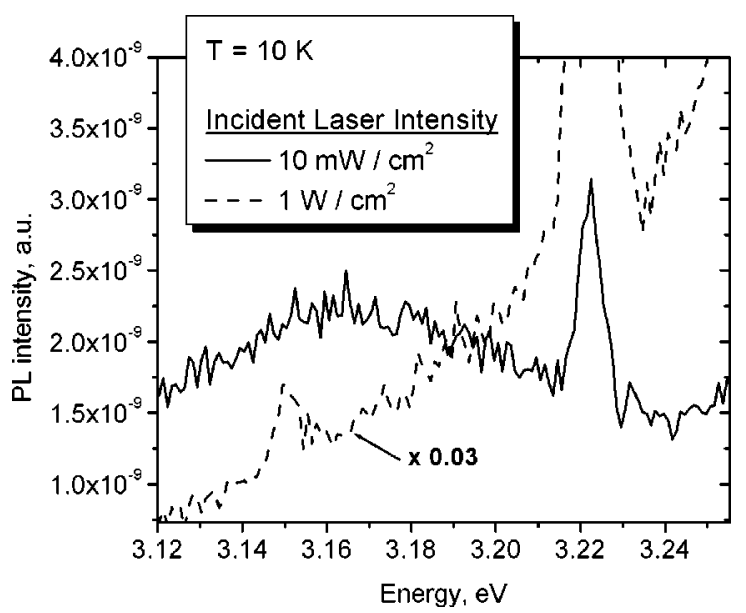

FIG. 5. Effect of incident power variation on the intensity of the violet emission. $10 \mathrm{~K}$ PL spectra of the RT-hydrogenated were taken at two different incident laser intensities: $10 \mathrm{~mW} / \mathrm{cm}^{2}$ (solid line) and $1 \mathrm{~W} / \mathrm{cm}^{2}$ (dashed line). The latter spectrum was multiplied by a factor of 0.03 to juxtapose with the former. This figure demonstrates that the violet feature is more pronounced at lower laser intensities.

dominated by the $3.374 \mathrm{eV}$ peak, which is usually attributed to a free (or a weakly trapped ${ }^{10}$ ) exciton recombination. The bound exciton peak band at $3.360 \mathrm{eV}$ is relatively weak. After hydrogenation, the bound-exciton peak dominates the spectrum at $90 \mathrm{~K}$, while the free-exciton transition is practically unobservable. We can see the distinct broad violet emission as well.

It is worth mentioning some important observations regarding that violet feature. It is relatively broad and is centered at approximately $3.15 \mathrm{eV}$. It is removed by a subsequent remote plasma hydrogenation at $450{ }^{\circ} \mathrm{C}$ (see Fig. 2). Temperature dependent PL experiments indicate that it is more prominent at relatively low temperatures. Furthermore, this emission is less pronounced at higher laser intensities. The latter statement is illustrated in Fig. 5, in which we superimpose the $10 \mathrm{~K} \mathrm{PL}$ spectra of two room-temperaturehydrogenated samples, in which the PL excitation intensity has been varied by 2 orders of magnitude, respectively.

PL results for emission in the visible range are shown in Fig. 6. Room temperature spectra in the visible range of the as-received and hydrogenated samples are very similar. They contain two distinct contributions: from the broad green band, related to deep-defect luminescence, and from a blue/ violet feature, associated with the rising edge of the nearband transitions. At low temperatures, the only change occurring in the as-received sample is an increase in emission intensity. At the same time, in the hydrogenated sample, the visible spectra change shape significantly at low temperatures. Hence, when one compares PL spectra taken at $9 \mathrm{~K}$ of the as-received sample and the hydrogenated sample, the difference is substantial; upon hydrogenation, the green emission is eliminated and the violet emission dominates the visible part of the spectrum.

\section{Low energy electron nanoluminescence results}

Further results were obtained employing low energy electron nanoluminescence (LEEN) spectroscopy, ${ }^{27}$ a low-

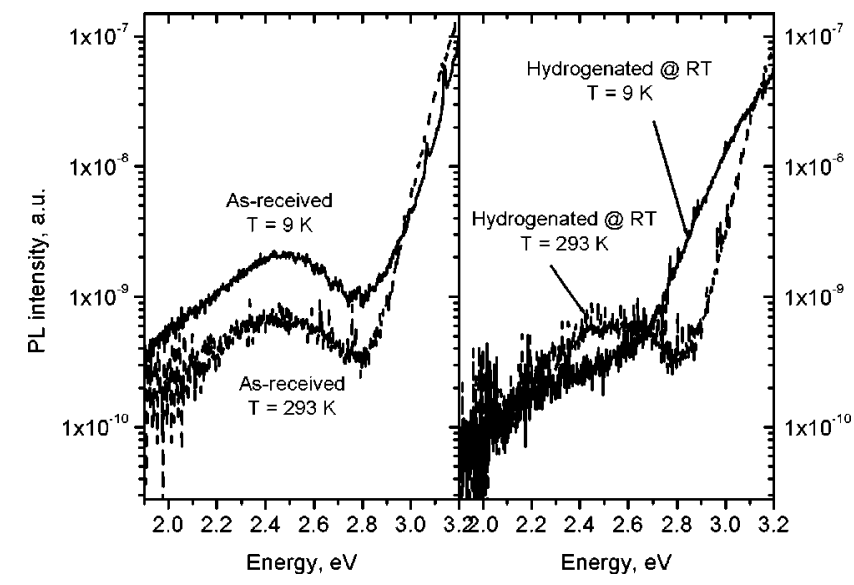

FIG. 6. Effect of hydrogenation on PL emission in the visible range. For the as-received sample, the green emission is increasing at low temperatures (left half). In the RT-hydrogenated sample, the visible spectrum is reshaped at low $T$, so that upon H-plasma treatment, the green emission is passivated and the visible luminescence is predominantly violet (right half). All spectra shown were taken with an incident intensity of $0.1 \mathrm{~W} / \mathrm{cm}^{2}$.

energy version of the depth-dependent CL spectroscopy. It is based on the dependence of excitation depth on electron beam energy, which increases on a keV scale. Figure 7 illustrates quantitatively the calculated relation between the electron beam energy and the depth of maximum electron-hole pair creation $U_{0}$ for the atomic and nucleon number and density values of wurtzite $\mathrm{ZnO}$.

Displayed in Fig. 8 are room-temperature LEEN spectra for the as-received sample and the samples hydrogenated at room temperature and at $450{ }^{\circ} \mathrm{C}$, respectively. The electron beam energies were $0.5,1.0,2.0$, and $3.0 \mathrm{keV}$. For the wurtzite $\mathrm{ZnO}$ crystal, these accelerating energies correspond to $U_{0}$ 's values of $\sim 3-\sim 30 \mathrm{~nm}$, as indicated in the graph. As one can see, room temperature hydrogenation increases the CL emission intensity, and this increase is most pronounced in the violet/near-UV range. The changes are also stronger close to the free surface of the specimen (dashed curves). Subsequent post-hydrogenation at $450{ }^{\circ} \mathrm{C}$ restores the inten-

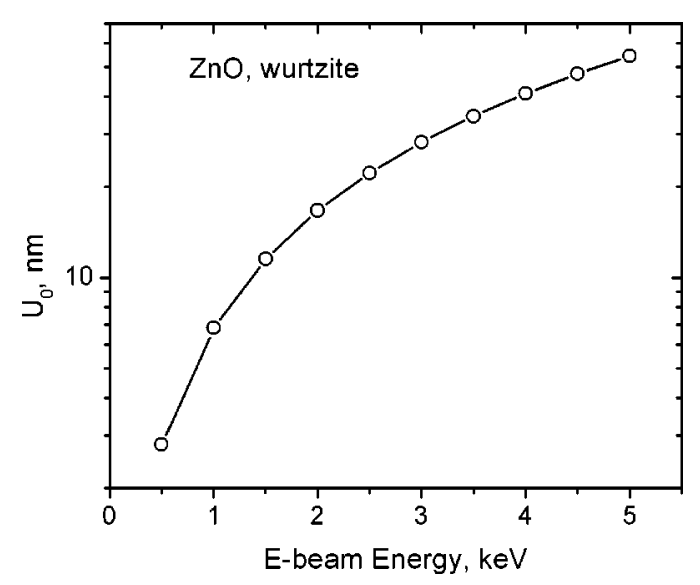

FIG. 7. Calculated dependence of the maximum energy dissipation depth $U_{0}$ on the electron beam energy for wurtzite $\mathrm{ZnO}$. The depth of excitation increases on a scale of tens of nanometers with electron beam energy increasing on a kiloelectron-volt scale. 


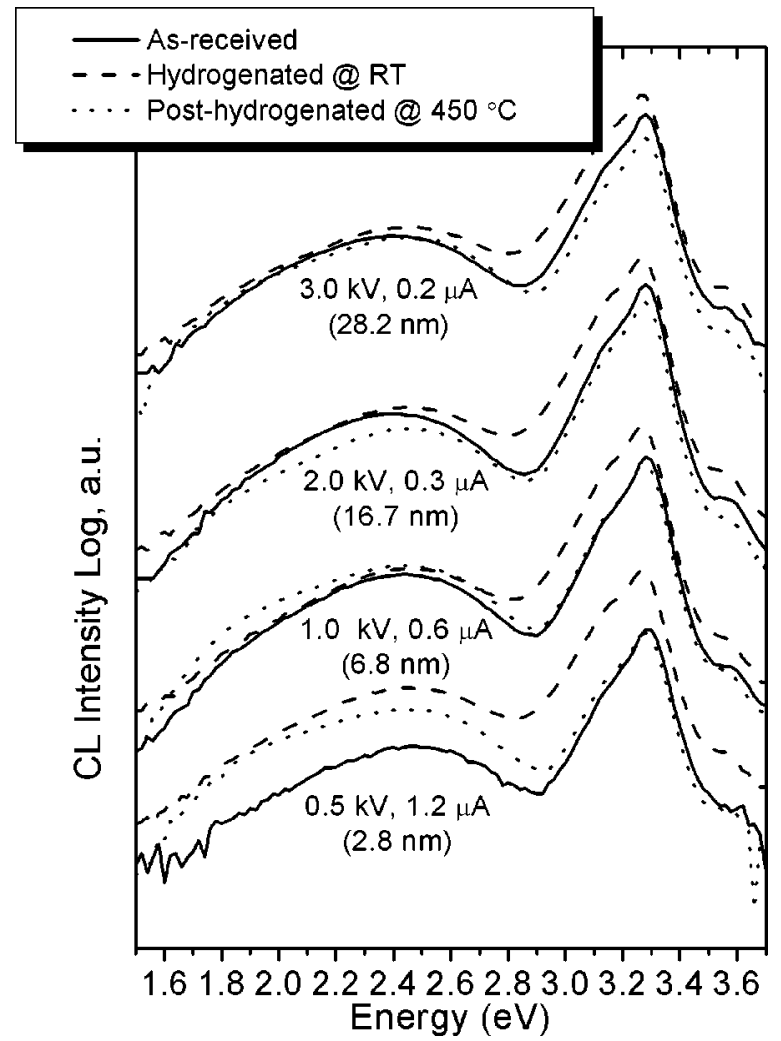

FIG. 8. Room temperature LEEN results for the four different sets of the electron beam parameters. Corresponding values of the depths of maximum energy absorption $U_{0}$ are given in parentheses. (Solid curves) Band edge and green emissions are observed for all the penetration depths. (Dashed curves) Room temperature remote plasma hydrogenation increases emission in the visible and UV ranges. This increase is greater in the blue-violet range and is most pronounced near the free surface, which suggests a characteristic hydrogen diffusion depth. (Dotted curves) Subsequent annealing restores prehydrogenation violet-UV features.

sity of the blue/violet emission (dotted curves), which is consistent with the PL results, described above.

\section{Discussion}

Controlling shallow donors, i.e., the contributors to the $n$-type conductivity in nominally undoped crystals, remains a major challenge in modifying the properties of $\mathrm{ZnO}$. To effectively remove or passivate them in an effort to obtain robustly $p$-type material, an unambiguous understanding of their nature must be attained. Recent strong evidence has linked shallow donors with the presence of hydrogen in $\mathrm{ZnO}{ }^{14-22}$ Results reported herein (see also Ref. 28) support this scenario and add further insight. For example, Fig. 3 shows an increase of the $I_{4} / I_{8}$ intensity ratio as a result of remote plasma hydrogenation. Previous studies $1,18,23,29-31$ have attributed $I_{4}$ to an exciton bound to a shallow donor, while $I_{8}$ has been assigned to an acceptor-bound exciton. ${ }^{18,32}$ The relative increase of the $I_{4}$ peak is consistent with the incorporation of hydrogen as a donor. In Refs. 1, 29, and 31, it was reported that this bound-exciton peak has been suppressed after annealing. We have processed those same samples with the remote H-plasma treatment as well, and the $I_{4}$ has reappeared. These studies are currently in progress and details will be reported in a separate article. The strong

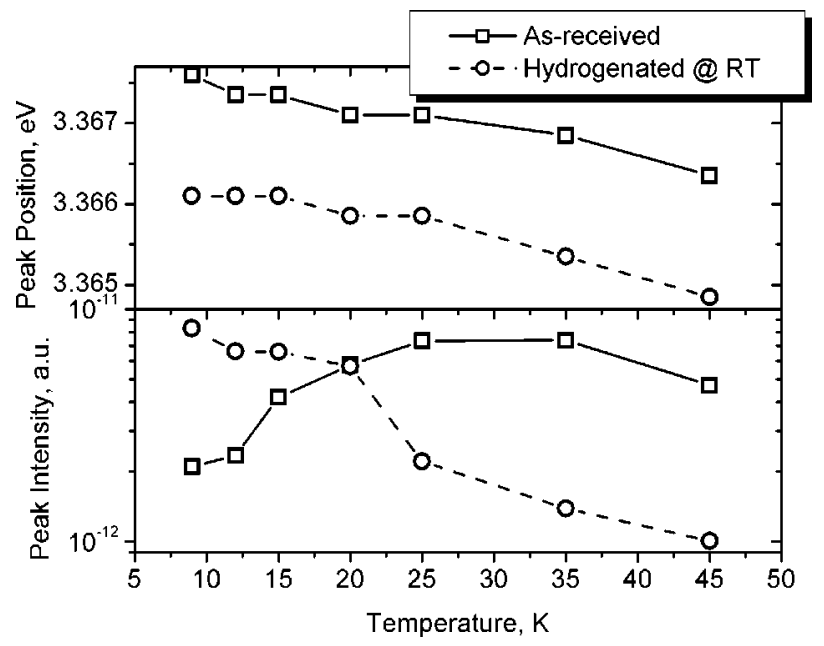

FIG. 9. Comparison of the temperature evolution of the peak position (top) and intensity (bottom) for the $I_{3}$ emission in the as-received sample (squares) and its counterpart in the RT-hydrogenated sample (circles). Incident intensity- $0.1 \mathrm{~W} / \mathrm{cm}^{2}$. In the temperature range $10-45 \mathrm{~K}$, the $I_{3}$ peak position remains more than $1 \mathrm{meV}$ above its equivalent in the H-plasma treated sample. The latter exhibits a distinct thermal quenching behavior, with an activation energy of a few $\mathrm{meV}$.

dependence of the $I_{4}$ intensity on the presence of hydrogen, described above, indicates a convincing connection between the $I_{4}$ line, shallow donor, and a hydrogen-related impurity.

Figure 3 also shows the appearance of another feature at $3.366 \mathrm{eV}$ as a result of the hydrogenation procedure. At $9 \mathrm{~K}$, the intensity of this peak is comparable to that of $I_{8}$. For the as-received sample at $9 \mathrm{~K}$, there is a weak feature apparent at $\sim 3.367 \mathrm{eV}$, which is the $I_{3}$ peak (e.g., Ref. 26). It seems natural to assume that the $3.366 \mathrm{eV}$ feature observed after hydrogenation is the shifted $I_{3}$ peak, unless one considers the thermal quenching behavior. In Fig. 9, we present a comparison of the temperature evolution of the peak intensity and position for the $I_{3}$ emission (as-received sample) and the $3.366 \mathrm{eV}$ feature (hydrogenated sample). In the temperature range between 10 and $45 \mathrm{~K}$, the $3.366 \mathrm{eV}$ peak retains the $\sim 1 \mathrm{meV}$ difference with the $I_{3}$ peak position, and, more importantly, exhibits a distinct thermal quenching response. A simple analysis of this peak indicates an activation energy of just a few meV, whereas the $I_{3}$ peak reveals a more complex behavior, with rising and falling edges of the curve. At the moment, the information we have is insufficient to speculate on the origins of this $3.366 \mathrm{eV}$ emission peak. The small activation energy makes it very distinct from other bound excitons. Recently, there was a report of two donor states, $\mathrm{Mu}_{\mathrm{I}}$ and $\mathrm{Mu}_{\mathrm{II}}$, found in $\mathrm{ZnO}$ as a result of muon implantation. ${ }^{33}$ The authors suggested that the $\mathrm{Mu}_{\mathrm{II}}$ state, with an activation energy of tens of $\mathrm{meV}$, is due to a donor located at the bond-center site $\mathrm{BC}_{\|}$, in good agreement with theoretical predictions and infrared-absorption experiments. ${ }^{14-16}$ At the same time, the $\mathrm{Mu}_{\mathrm{I}}$ center was found to have an activation energy of only a few $\mathrm{meV}$, and was attributed by the authors to the antibonding $\mathrm{AB}_{\mathrm{O}, \|}$ site.

Figures 5 and 6 illustrate changes occurring in the visible and near-UV PL emission as a result of hydrogenation. There is a clear evidence of two competing types of emission: green and violet. The green emission band has evoked 
a long, and still unresolved, debate on its nature. The most common components discussed are $\mathrm{V}_{\mathrm{Zn}},{ }^{34,35} \mathrm{~V}_{\mathrm{O}},{ }^{36,37}$ and $\mathrm{Cu}^{38}$ It was mentioned above that the violet emission appears in our hydrogenated samples mostly at low temperatures and low laser intensities, conditions under which the green emission is fully suppressed. Several groups ${ }^{8-10,14}$ have reported previously on the suppression of the green band as a result of applied hydrogen plasma. They have suggested a model in which green-emission centers are passivated by hydrogen. In particular, it was proposed ${ }^{14}$ that those centers are $\mathrm{V}_{\mathrm{Zn}}$ acceptors that form $\mathrm{V}_{\mathrm{Zn}} \mathrm{H}_{2}$ complexes upon hydrogenation. If we assume relevance of this "two-atom passivation" model, then the observed violet emission can be explained by the presence of another radiative recombination center (possibly related to a different native defect) with a smaller recombination efficiency and low saturation levels. Emission via "violet centers" may occur when most of the green centers are passivated, and when the low laser intensities allow observation of those still relatively unsaturated levels. Defect levels consistent with the position of the violet band should be $\sim 0.2-0.3 \mathrm{eV}$ deep. Some native defects with similar transition energies have been suggested by numerous authors $\left(\right.$ e.g., $\left.\mathrm{O}_{i}\right) .{ }^{39}$ It should be mentioned, that the violet luminescence at energies close to $3.15 \mathrm{eV}$ has been communicated before ${ }^{40-44}$ for $\mathrm{ZnO}$ specimens grown and processed with various methods. In particular, a competition between the green and violet emissions was reported in Ref. 44, although the authors have attributed it to a temperature-driven change in stoichiometry.

Remote hydrogen plasma also suppresses free-exciton recombination and significantly reduces TES line intensities (see Figs. 2, 3, and 4) in the low-temperature PL spectra. Those phenomena have been consistently observed for all the hydrogenated samples studied. An explanation for this behavior has yet to be provided.

Importantly, most of changes in the violet/UV luminescence described above are removed by a subsequent hydrogen plasma treatment at $450{ }^{\circ} \mathrm{C}$ (see Fig. 2). It should be mentioned that these results showing the reversible effects of hydrogen annealing are reproducible from sample to sample. This return of the UV/violet emission to its initial intensity upon annealing can be explained by the outdiffusion of hydrogen. Hydrogen outdiffusion has already been observed and reported ${ }^{13,45}$ for $\mathrm{H}$ implants in $\mathrm{ZnO}$. Because of the observed reversibility, we argue that the spectral changes are unlikely to be caused by any contamination from the chamber walls. Rather they must result from the hydrogen plasma itself.

Room temperature LEEN results (Fig. 7) agree with our PL comments and provide additional information on the nature of hydrogen incorporation. Low excitation levels $\left(\sim 10 \mathrm{~mW} / \mathrm{cm}^{2}\right)$ allow observation of violet emission in the hydrogenated samples. Indeed, comparing the spectra of the as-received and room temperature (RT)-hydrogenated samples, one can see a relative increase of the CL signal primarily in the violet/near UV range. The effect is observed to propagate to depths exceeding our probe depths ( $\sim 90 \mathrm{~nm}$ for a $3 \mathrm{keV}$ primary electron beam). This is consistent with the secondary ion mass spectrometry studies ${ }^{7}$ showing rapid diffusion of hydrogen in $\mathrm{ZnO}$. The depth dependence observed with LEEN on our samples suggests a somewhat larger characteristic diffusion length for hydrogen compared to the one reported for direct H-plasma processing. ${ }^{11}$

The increase of the green emission at the surface upon RT hydrogenation can be accounted for by an increase of the near-surface concentration of the damage-related green emission centers. Our AFM images indicate (see Fig. 1) that the hydrogen plasma produces a certain amount of surface degradation. On the other hand, an increase in the effective area of the free surface enhances somewhat the probability of hydrogen incorporation. This may explain the relatively greater increase of the violet signal in the $0.5 \mathrm{keV}$ LEEN spectra.

Subsequent H-plasma annealing at $450{ }^{\circ} \mathrm{C}$ reduces the emission in the violet-UV range, also consistent with our PL observations (cf. Fig. 2).

\section{SUMMARY}

We have found that a remote hydrogen plasma treatment at room temperature induces significant changes in the luminescence properties of $\mathrm{ZnO}$. The results presented here are consistent with the picture of hydrogen diffusing into and reacting with the material. In particular, there is a strong correlation observed between the presence of hydrogen and the intensity of the spectral features, such as the $I_{4}$ boundexciton line, commonly attributed to shallow donors. These observations could be important for both fundamental and applied domains. Clarification of the nature of the prevalent $n$-type conductivity and control of the shallow donors should be useful for engineering the optoelectronic properties of $\mathrm{ZnO}$. We have also reported on a strong effect produced by the hydrogen plasma in the visible spectral rangesuppression of the green luminescence and an ensuing shift of the visible emission into the violet. This result alone could yield potential applications. We suggest that the reversibility of the PL and CL spectra, induced by the postannealing, is due to the outdiffusion of hydrogen and indicates possible ways to control the optical parameters of $\mathrm{ZnO}$.

\section{ACKNOWLEDGMENTS}

The authors would like to thank G. Lucovsky for useful discussions and hardware provided. The authors would also like to acknowledge the support by: the Department of Energy (Grant No. DE-FG0297ER45666), Office of Naval Research (Grant No. N00014-00-1-0042), and National Science Foundation (Grant No. DMR 0076362). D.C.L. was supported by Air Force Contract No. F3615-00-C-5402.

${ }^{1}$ D. C. Look, Mater. Sci. Eng., B B80, 383 (2001), and references therein.

${ }^{2}$ E. Mollwo, Z. Phys. 138, 478 (1954).

${ }^{3}$ S. Kohiki, M. Nishitani, T. Wada, and T. Hirao, Appl. Phys. Lett. 64, 2876 (1994)

${ }^{4}$ S. J. Baik, J. H. Jang, C. H. Lee, W. Y. Cho, and K. S. Lim, Appl. Phys. Lett. 70, 3516 (1997).

${ }^{5}$ Y. Natsume and H. Sakata, J. Mater. Sci. 12, 87 (2001).

${ }^{6}$ Y. Natsume and H. Sakata, Mater. Chem. Phys. 78, 170 (2002).

${ }^{7}$ B. Theys, V. Sallet, F. Jomard, A. Lusson, J.-F. Rommeluere, and Z. Teukam, J. Appl. Phys. 91, 3922 (2002). 
${ }^{8}$ T. Sekiguchi, N. Ohashi, and Y. Terada, Jpn. J. Appl. Phys., Part 2 36, L289 (1997).

${ }^{9}$ T. Sekiguchi, N. Ohashi, and H. Yamane, Solid State Phenom. 63-64, 171 (1998).

${ }^{10}$ N. Ohashi, T. Ishigaki, N. Okada, T. Sekiguchi, I. Sakaguchi, and H. Haneda, Appl. Phys. Lett. 80, 2869 (2002).

${ }^{11}$ J.-M. Lee, K.-K. Kim, S.-J. Park, and W.-K. Choi, Appl. Phys. Lett. 78, 3842 (2001).

${ }^{12}$ K. Minegishi, Y. Koiwai, Y. Kikuchi, K. Yano, M. Kasuga, and A. Shimizu, Jpn. J. Appl. Phys., Part 2 36, L1453 (1997).

${ }^{13}$ K. Ip et al., Appl. Phys. Lett. 82, 385 (2003).

${ }^{14}$ E. V. Lavrov, J. Weber, F. Börnert, C. G. Van de Walle, and R. Helbig, Phys. Rev. B 66, 165205 (2002).

${ }^{15}$ C. G. Van de Walle, Phys. Rev. Lett. 85, 1012 (2000).

${ }^{16}$ C. G. Van de Walle, Physica B 308-310, 899 (2001).

${ }^{17}$ C. G. Van de Walle, Phys. Status Solidi B 229, 221 (2002).

${ }^{18} \mathrm{~K}$. Thonke, Th. Gruber, N. Teofilov, R. Schonfelder, A. Waag, and R. Sauer, Physica B 308-310, 945 (2001).

${ }^{19}$ S. F. J. Cox et al., Phys. Rev. Lett. 86, 2601 (2001).

${ }^{20}$ S. F. J. Cox, E. A. Davis, P. J. C. King, J. M. Gil, H. V. Alberto, R. C. Virão, J. Piroto Duarte, N. Ayres de Campos, and R. L. Lichti, J. Phys.: Condens. Matter 13, 9001 (2001).

${ }^{21}$ D. M. Hofmann, A. Hofstaetter, F. Leiter, H. Zhou, F. Henecker, B. K. Meyer, S. B. Orlinskii, J. Schmidt, and P. G. Baranov, Phys. Rev. Lett. 88, 045504 (2002).

${ }^{22}$ M. D. McCluskey, S. J. Jokela, K. K. Zhuravlev, P. J. Simpson, and K. G. Lynn, Appl. Phys. Lett. 81, 3807 (2002).

${ }^{23}$ D. C. Look, D. C. Reynolds, J. R. Sizelove, R. L. Jones, C. W. Litton, G. Cantwell, and W. C. Harsch, Solid State Commun. 105, 399 (1998).

${ }^{24}$ Original idea suggested in: G. Lucovsky, D. V. Tsu, S. S. Kim, R. J. Markunas, and G. G. Fountain, Appl. Surf. Sci. 39, 33 (1989).

${ }^{25}$ A. P. Young, J. Jones, and L. J. Brillson, J. Vac. Sci. Technol. A 17, 2692 (1999).

${ }^{26}$ D. C. Reynolds, C. W. Litton, and T. C. Collins, Phys. Rev. 140, A1726 (1965).
${ }^{27}$ L. J. Brillson, H. W. Richter, M. L. Slade, B. A. Weinstein, and Y. Shapira, J. Vac. Sci. Technol. A 13, 1924 (1995).

${ }^{28}$ Y. M. Strzhemechny, J. Nemergut, J. Bae, D. C. Look, and L. J. Brillson, Mater. Res. Soc. Symp. Proc. 744, M3.9.1 (2003).

${ }^{29}$ D. C. Reynolds, D. C. Look, B. Jogai, C. W. Litton, T. C. Collins, W. C. Harsch, and G. Cantwell, Phys. Rev. B 57, 12151 (1998).

${ }^{30}$ D. C. Look, D. C. Reynolds, C. W. Litton, R. L. Jones, D. B. Eason, and G. Cantwell, Appl. Phys. Lett. 81, 1830 (2002).

${ }^{31}$ D. C. Look, R. L. Jones, J. R. Sizelove, N. Y. Garces, N. C. Giles, and L. E. Halliburton, Phys. Status Solidi A 195, 171 (2003)

${ }^{32}$ J. Gutowsky, N. Presser, and I. Broser, Phys. Rev. B 38, 9746 (1988).

${ }^{33}$ K. Shimomura, K. Nishiyama, and R. Kadono, Phys. Rev. Lett. 89, 255505 (2002)

${ }^{34}$ A. F. Kohan, G. Ceder, D. Morgan, and C. G. Van de Walle, Phys. Rev. B 61, 15019 (2000)

${ }^{35}$ D. C. Reynolds, D. C. Look, B. Jogai, J. E. Van Nostrand, R. Jones, and J. Jenny, Solid State Commun. 106, 701 (1998).

${ }^{36}$ F. Leiter, H. Zhou, F. Henecker, A. Hofstaetter, D. M. Hofmann, and B. K. Meyer, Physica B 308-310, 908 (2001).

${ }^{37}$ K. Vanheusden, W. L. Warren, C. H. Seager, D. R. Tallant, and J. A. Voigt, J. Appl. Phys. 79, 7983 (1996).

${ }^{38}$ N. Y. Garces, L. Wang, L. Bai, N. C. Giles, L. E. Halliburton, and G. Cantwell, Appl. Phys. Lett. 81, 622 (2002), and references therein.

${ }^{39}$ S. B. Zhang, S.-H. Wei, and A. Zunger, Phys. Rev. B 63, 075205 (2001).

${ }^{40}$ T. V. Butkhuzi, A. V. Bureyev, A. N. Georgobiani, N. P. Kekelidze, and T. G. Khulordava, J. Cryst. Growth 117, 366 (1992).

${ }^{41}$ A. N. Georgobiani, M. B. Kotlyarevskii, V. V. Kidalov, L. S. Lepnev, and I. V. Rogozin, Inorg. Mater. (Transl. of Neorg. Mater.) 37, 1095 (2001).

${ }^{42}$ Q. P. Wang, D. H. Zhang, Z. Y. Xue, and X. T. Hao, Appl. Surf. Sci. 201, 123 (2002).

${ }^{43}$ B. X. Lin, Z. X. Fu, and Y. B. Jia, Appl. Phys. Lett. 79, 943 (2001).

${ }^{44}$ B. J. Jin, S. Im, and S. Y. Lee, Thin Solid Films 366, 107 (2000).

${ }^{45}$ K. Ip et al., Appl. Phys. Lett. 81, 3996 (2002). 